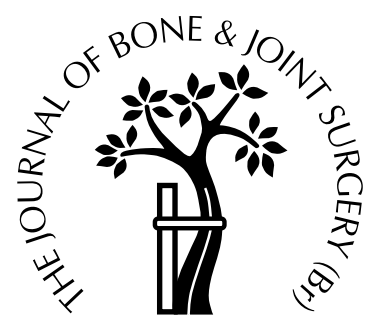

\title{
ORTHOPAEDIC BONE DRILLS - CAN THEY BE IMPROVED?
}

\author{
TEMPERATURE CHANGES NEAR THE DRILLING FACE
}

COLIN NATALI, PAUL INGLE, JOHN DOWELL

From Broomfield Hospital, Chelmsford, England

We studied the various drill bits available for engineering purposes, and compared them with standard orthopaedic drill bits, using continuous temperature recording at $0.5 \mathrm{~mm}, 1.0 \mathrm{~mm}$ and $1.5 \mathrm{~mm}$ from the edge of a $2.5 \mathrm{~mm}$ hole as it was drilled in fresh cadaver human tibia.

We found that some commercially available drill bits performed better than their orthopaedic equivalents, producing significantly less thermal injury to the surrounding bone and halving the force required for cortical penetration. Our work suggests that the optimal bit for orthopaedic purposes should have a split point and a quick helix. Theoretical knowledge of cutting technology predicts that the addition of a parabolic flute will further reduce thermal damage. Further work is being done on other drill sizes used in orthopaedic practice and on new custom-designed bits.

J Bone Joint Surg [Br] 1996;78-B:357-62.

Received 3 November 1995; Accepted after revision 13 December 1995

Many orthopaedic operations involve drilling and tapping before the insertion of screws into bone. It is known that an excessive rise in temperature around a drill hole will cause thermal necrosis of bone, and it has been shown that temperatures of over $50^{\circ} \mathrm{C}$ are associated with irreversible changes in the structure and physical properties of bone (Bonfield and Li 1968). The immediate effect on the physical structure and the later effect on the cellular components both prejudice the hold of the screw as necrotic bone is resorbed, reducing the stability and strength of the fixation.

C. Natali, FRCS, Senior Orthopaedic Registrar

J. Dowell FRCS, Consultant Orthopaedic Surgeon Broomfield Hospital, Court Road, Broomfield, near Chelmsford, Essex CM1 5ET, UK.

P. Ingle, MSc, Senior Lecturer (Materials and Metallurgy)

Anglia Polytechnic University, Chelmsford, Essex CM1 1LL, UK.

Correspondence should be sent to Mr C. Natali at The Royal London Hospital, Whitechapel Road, London E1 1BB, UK.

(C) 1996 British Editorial Society of Bone and Joint Surgery 0301-620X/96/31179\$2.00

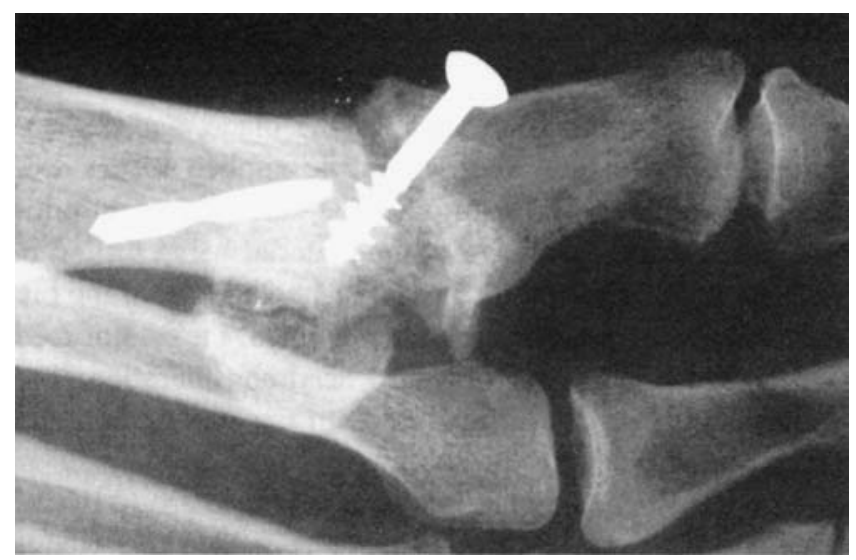

Fig. 1

A broken drill.

The presence of necrotic tissue may delay healing and predispose to infection.

Blunt drill bits will generate higher temperatures and even smoke, while the increased force required for penetration causes poor control of the drill, uncontrolled bursting through the cortex or drill breakage (Fig. 1).

The thermal effects of drill bits have been reported for animal bone (Saha, Pal and Albright 1982; Andrianne et al 1987), polymethylmethacrylate bone cement (Saha et al 1982) and human bone (Matthews and Hirsch 1972); various design features of drill bits are thought to influence the amount of thermal injury (Matthews and Hirsch 1972; Saha et al 1982; Matthews, Green and Goldstein 1984; Fuchsberger 1987). These studies do not appear to have changed current designs of orthopaedic drill bits. Modern drilling technology is capable of improving drill bits to reduce the risk of thermal necrosis around a surgical drill hole. Previous investigators have used carefully controlled feed rates, and some used speeds in excess of the 800 revolutions per minute provided by standard orthopaedic drivers. To relate our results directly to conditions in the operating room, we used a drill turning at 800 revolutions per minute, with hand pressure only.

\section{DRILL DESIGN AND TERMINOLOGY}

There is a correct angle at which a blade should be applied when cutting: sharpening a pencil with a knife is possible 


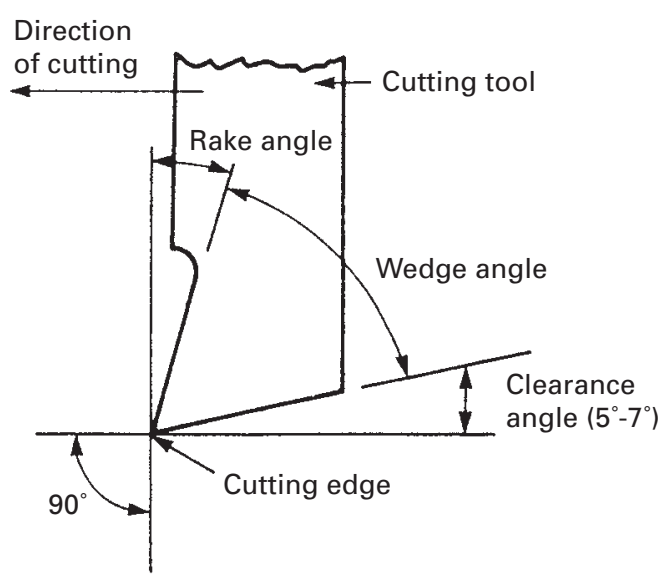

Fig. 2

Diagram of a simple cutting edge to show the important angles (see text).

only with the appropriate angle of the blade, and a sharp edge. These two principles should be applied to the drill bits used in orthopaedic surgery. The selection of an optimal bit requires knowledge of the material being drilled in order to match this to the physical characteristics of the bit. Other parameters such as the force applied, the rate of feed and the speed of the drill bit also need consideration. The characteristics of the bit include both the cutting end and the spiral (or helix) of the shaft.

The cutting face. Any cutting edge is characterised by the rake angle and the clearance angle (Fig. 2). The wedge angle is that between the cutting face and the flank, while the rake is the angle at which the cutting face is presented to the material. The clearance angle is the angle by which the flank of the drill clears the material. These terms apply to any cutting tool from penknife to drill bit.

The point of a drill bit can be further characterised by the point angle, the flank and the chisel edge (Figs 3a and 3b). The point angle is that between the two cutting edges measured in a sagittal plane and in standard orthopaedic drill bits
(Stratec Medical, Welwyn Garden City, UK) it is $90^{\circ}$. The ideal point angle depends on the material being drilled, and standard reference values in engineering recommend this angle for aluminium, copper and plastics. The flank is the flat part of the drill when viewed end-on (Fig. 3b); this surface is not totally in contact with the bond surface, but separated from it by the clearance angle (Fig. 3c). The flank of the drill represents a large surface area for friction and the generation of heat. This can be reduced by increasing the clearance angle halfway along its surface, and this type of point is termed a split point (Fig. 4). The term 'chisel edge' refers to the tip of the drill bit at the apex of the point angle. The shaft and the helix. The helix of a drill bit is measured as the helix angle (see Fig. 3c) and can be defined as slow, standard or quick, representing small, standard and large helix angles, respectively. A quick helix has more turns per unit length than a slow helix (Fig. 5). A slow helix is used to drill material from which debris clears easily, such as brass or cast iron, in conjunction with a large point angle. A fast helix is required for materials which must be cleared quickly to avoid blocking the flutes.

The flute itself may be parabolic in section (Fig. 5), termed a worm-pattern helix; this offers improved clearance of debris and allows higher feed rates of drill advancement. The length of the helix will influence the effective clearance of debris from deep holes, such as both cortices of a femur. The 'web' or core thickness is the term applied to the smallest distance between the flutes of a bit.

Characteristics of bone. The physical characteristics of bone vary considerably with its state. When it is dry, it is said to be 'short chipping', since the debris is generated in small particles that are easily cleared by a drill bit. Other short chipping materials are brass, cast iron and hard steel and the optimal helix angle for them is small (a slow helix). Most standard orthopaedic drill bits have this type of helix (see Fig. 2), but at operation the debris is wet and mixed with medullary fat. In this state bone is no longer short chipping and the flutes of a slow helix drill will clog easily. On theoretical grounds a bone drill bit should therefore have a quick helix.

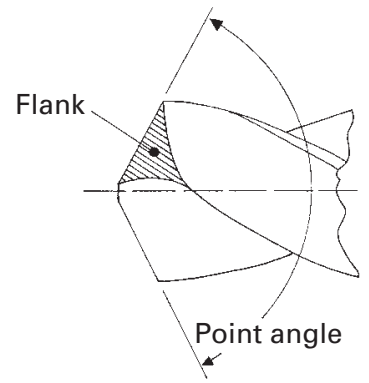

Fig. 3a

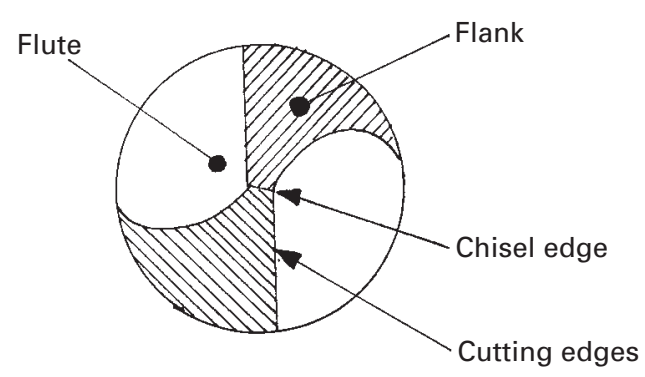

Fig. 3b

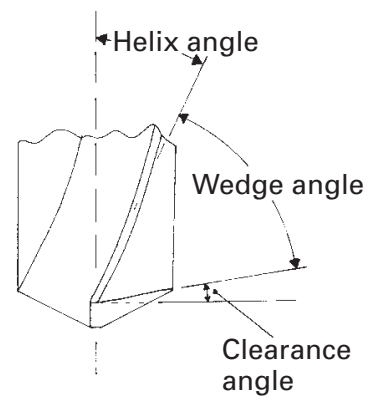

Fig. 3c

Line drawings of a standard drill bit showing a) the flank and point angle in profile, b) the flank, flutes and chisel and cutting edges viewed end-on and c) the helix, wedge and clearance angles. 
Table I. Details of the five tested bits

\begin{tabular}{lclll}
\hline Drill bit & Point angle (degrees) & Point type & Spiral type & Notes \\
\hline Used orthopaedic & 90 & Standard & Slow & $\begin{array}{l}\text { Cutting edges visibly } \\
\text { blunt }\end{array}$ \\
$\begin{array}{l}\text { Standard orthopaedic } \\
\text { with blocked flutes }\end{array}$ & 90 & Standard & $\begin{array}{l}\text { Slow with bone } \\
\text { debris }\end{array}$ & Flutes blocked \\
$\begin{array}{l}\text { New orthopaedic } \\
\text { High-speed twist }\end{array}$ & 90 & Standard & Slow & \\
'Bullet' drill & 118 & Standard & Quick & Commercial (Bosch) \\
& 118 & Split & Quick & $\begin{array}{l}\text { Commercial (Black } \\
\text { and Decker) }\end{array}$ \\
\hline
\end{tabular}

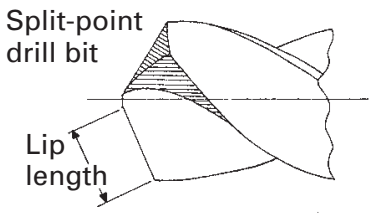

Fig. 4a

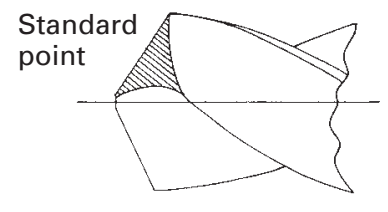

Fig. 4b
Comparison of a) the split-point bit and b) the standard bit.

The optimal drill. The point angle of the drill bit is important and there is no agreement on which offers the best results. Saha et al (1982) recommend $118^{\circ}$ but Fuchsberger (1987) recommends $70^{\circ}$ to $75^{\circ}$. Theory predicts that a split point would reduce friction, and that a quick helix is needed to clear the bone debris efficiently. This would also be improved by the use of a parabolic flute. Such a drill bit would be more efficient, generate minimal friction, and reduce the production of thermal energy. The characteristics of the drills which we tested are shown in Table I; the 'Bullet drill' comes closest to being ideal for drilling bone.

\section{MATERIALS AND METHODS}

We investigated five different $2.5 \mathrm{~mm}$ drill bits:

1) a new standard orthopaedic bit;

2) a used standard orthopaedic bit retrieved from a small fragment set;

3) a standard orthopaedic bit, with its flutes deliberately blocked by multiple drilling with no clearance of debris;

4) a high-speed steel twist bit (Bosch); and

5) a split-point high-speed steel bit (the Black and Decker 'Bullet' drill bit).

Preliminary tests showed that consistent results could be obtained only when drilling was carried out in a thermostatically-controlled cabinet held at $30^{\circ} \mathrm{C}$. We used fresh cadaver tibiae collected within 24 hours of death, having been kept at $4{ }^{\circ} \mathrm{C}$ and then used on the same day from donors with a mean age of 60 years (56 to 65). All were males who had died from cerebrovascular or cardiovascular disease.

A section of tibial diaphysis was cut into $8 \mathrm{~cm}$ pieces and the cut surfaces inspected. Cortex of approximately $4 \mathrm{~mm}$
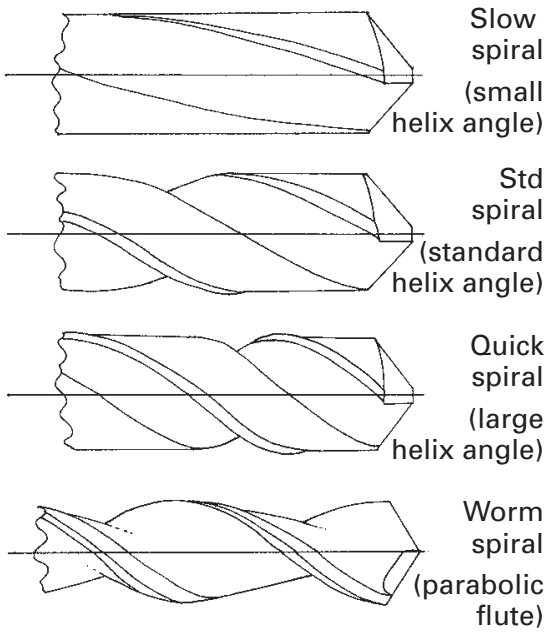

Fig. 5

Drawings showing variations in helix angle and a worm spiral bit. was selected for use, and its flat face was cleared of soft tissue and placed on the table of a computer numerical controlled drill (Match Maker CNC 600 Milling Machine with Numericon 850 controller; Yamazen Machines Ltd, Kingston-upon-Thames, UK). Holes of diameter $0.5 \mathrm{~mm}$ were made for thermocouples to be inserted at $0^{\circ}, 120^{\circ}$ and $240^{\circ}$ radii from the proposed drill centre (Fig. 6). These holes were $0.5,1.0$, and $1.5 \mathrm{~mm}$ from the edge of the final drill hole. A small surface dent was made at the centre of the thermocouple nest to allow accurate experimental drilling. A number of test sites were prepared in this manner.

The bone was then transferred to the test cabinet in a water-bath at $38^{\circ} \mathrm{C}$ (Fig. 7). The thermocouples (K series) were inserted into the predrilled holes and connected to a temperature logger (Kane May KM1400 Data logger, Welwyn Garden City, UK), and by a serial link to a personal computer (IBM $48666 \mathrm{mHz}$ ). The test bone was placed on a drill platform which allowed measurement of the force applied. Recording was started when the bone temperature records showed $37^{\circ} \mathrm{C}$. A commercial electric drill was used 


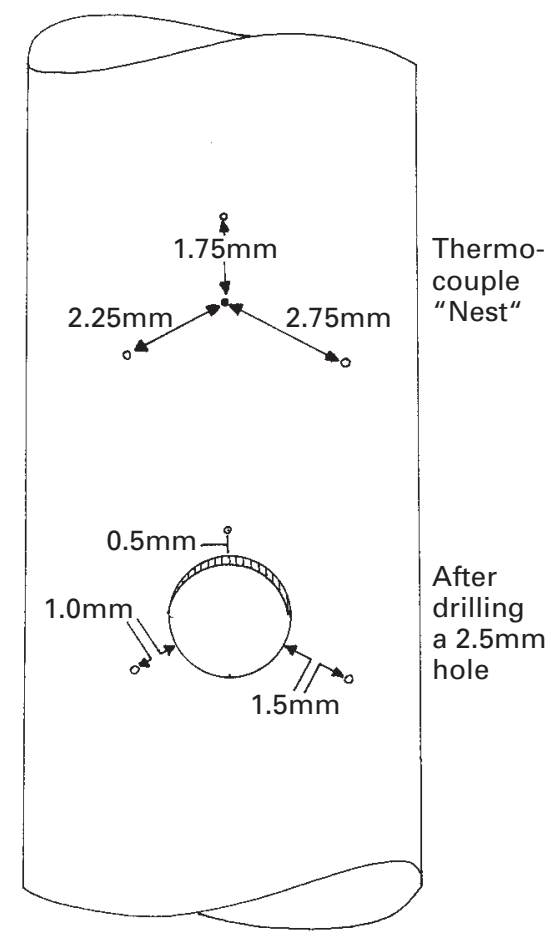

Fig. 6a

Fig. $6 b$

Diagrams showing a) the pre-drilled thermocouple holes and b) after drilling with the test bit.

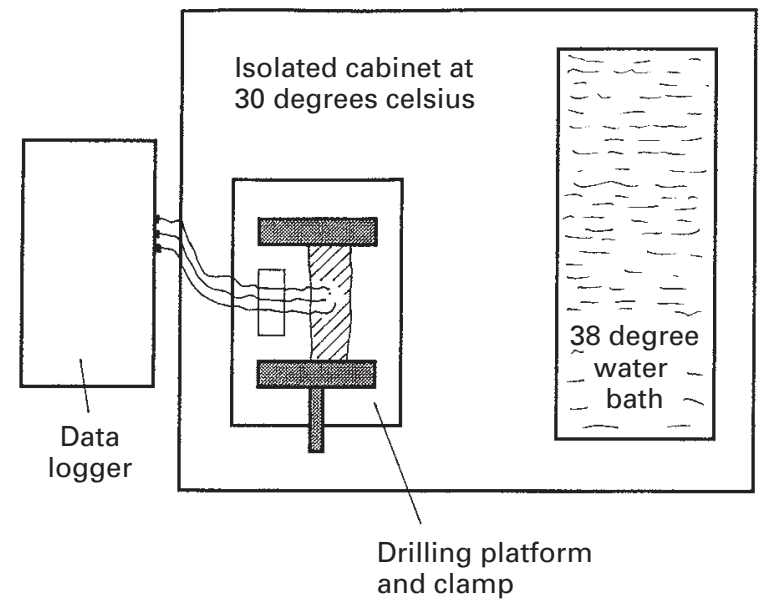

Fig. 7

Diagram of the experimental equipment.

by hand at 800 revolutions per minute and the force noted while a single cortex was drilled. The temperature recordings continued until the bone had cooled to $37^{\circ} \mathrm{C}$ again.

The true cortical thickness was then measured and provided that this was between 4 and $5 \mathrm{~mm}$, the recording was retained. If the cortical thickness was different or if drilling became skewed and damaged a thermocouple the reading was discarded.
Table II. Mean maximum temperatures (degrees) at $0.5 \mathrm{~mm}$ from the edge of the drill hole

\begin{tabular}{lll}
\hline Drill bit & $\begin{array}{l}\text { Max } \\
\text { temp }\end{array}$ & $\mathbf{9 5 \%}$ CI \\
\hline Used orthopaedic & 48.72 & 0.6 \\
Standard orthopaedic with blocked flutes & 54.24 & 0.4 \\
New orthopaedic & 42.7 & 0.4 \\
High-speed twist & 40.5 & 0.6 \\
'Bullet' drill & 40 & 0.3 \\
\hline
\end{tabular}

Table III. Mean duration of heating over $40^{\circ} \mathrm{C}$ in seconds for each bit

\begin{tabular}{ll}
\hline Drill bit & Duration \\
\hline Used orthopaedic & 35 \\
Standard orthopaedic with blocked flutes & 34.4 \\
New orthopaedic & 10 \\
High-speed twist & 4 \\
'Bullet' drill & 0 \\
\hline
\end{tabular}

Results were obtained for ten holes which met these criteria for each drill type. These were compared by analysis of variance (Sidak 1967) using STATA statistical software (College Station, Texas).

\section{RESULTS}

An average result was obtained for each type of drill bit for all ten holes. The resultant curves for each of the three thermocouples are shown in Figure 8. The highest local temperatures were generated with the standard orthopaedic drill with artificially blocked flutes, and were sustained for longer. The new Stratec orthopaedic drill created less rise in temperature, but the lowest temperature changes were obtained with the split-point, fast helix drill (Black and Decker 'Bullet' drill). Figure 9 shows the superimposed graphs of the average temperature recordings for each drill made at $0.5 \mathrm{~mm}$ from the drill edge.

Table II shows the maximum temperature rise for each drill with a 95\% confidence interval. The use of a Sidak multiple comparison test showed that the small difference between the standard orthopaedic drill bit with blocked flutes and the old drill was significant with $\mathrm{p}=0.045$. Between all other drill bit types the $\mathrm{p}$ values of the differences were highly significant $(\mathrm{p}<0.0005)$.

The data were replotted to show duration above $40^{\circ} \mathrm{C}$ at $0.5 \mathrm{~mm}$ from the drill hole. There were significant differences between the Stratec, twist and Bullet drills (Table III).

The force required to penetrate the cortex was difficult to measure; the drilling was by hand at non-constant feed rates, since we considered that this best represented a surgi- 


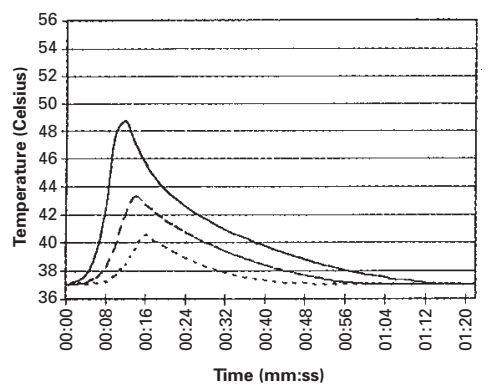

Fig. 8a

Used standard orthopaedic drill bit.

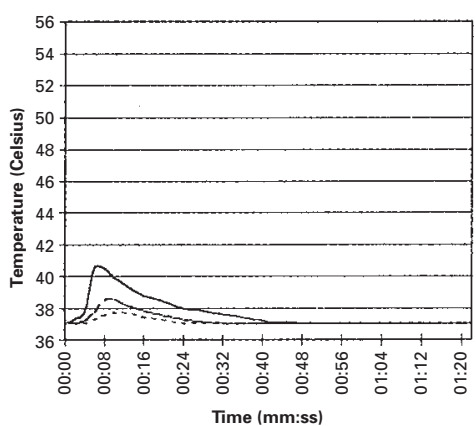

Fig. 8d

Commercial high-speed twist drill.

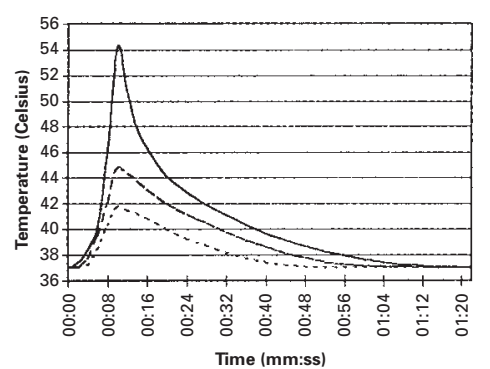

Fig. $8 \mathrm{~b}$

Standard orthpaedic drill bit with blocked flutes.

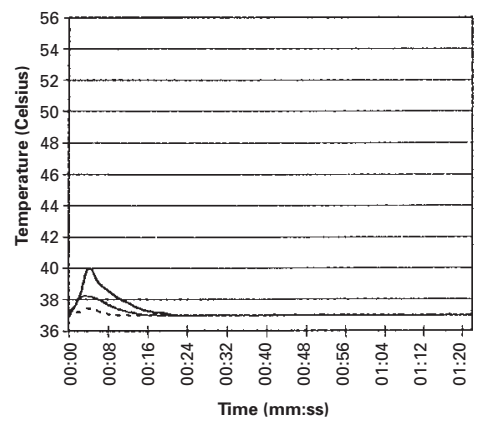

Fig. $8 \mathrm{e}$

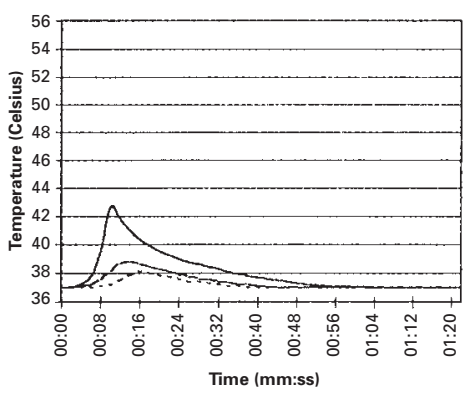

Fig. 8c

New standard orthopaedic drill bit.

$$
\begin{array}{r}
-0.5 \mathrm{~mm} \\
-\cdots-1.0 \mathrm{~mm} \\
\cdots \cdots 1.5 \mathrm{~mm}
\end{array}
$$

Graphs of the mean temperatures recorded from each of the three thermocouples for each of the bits.

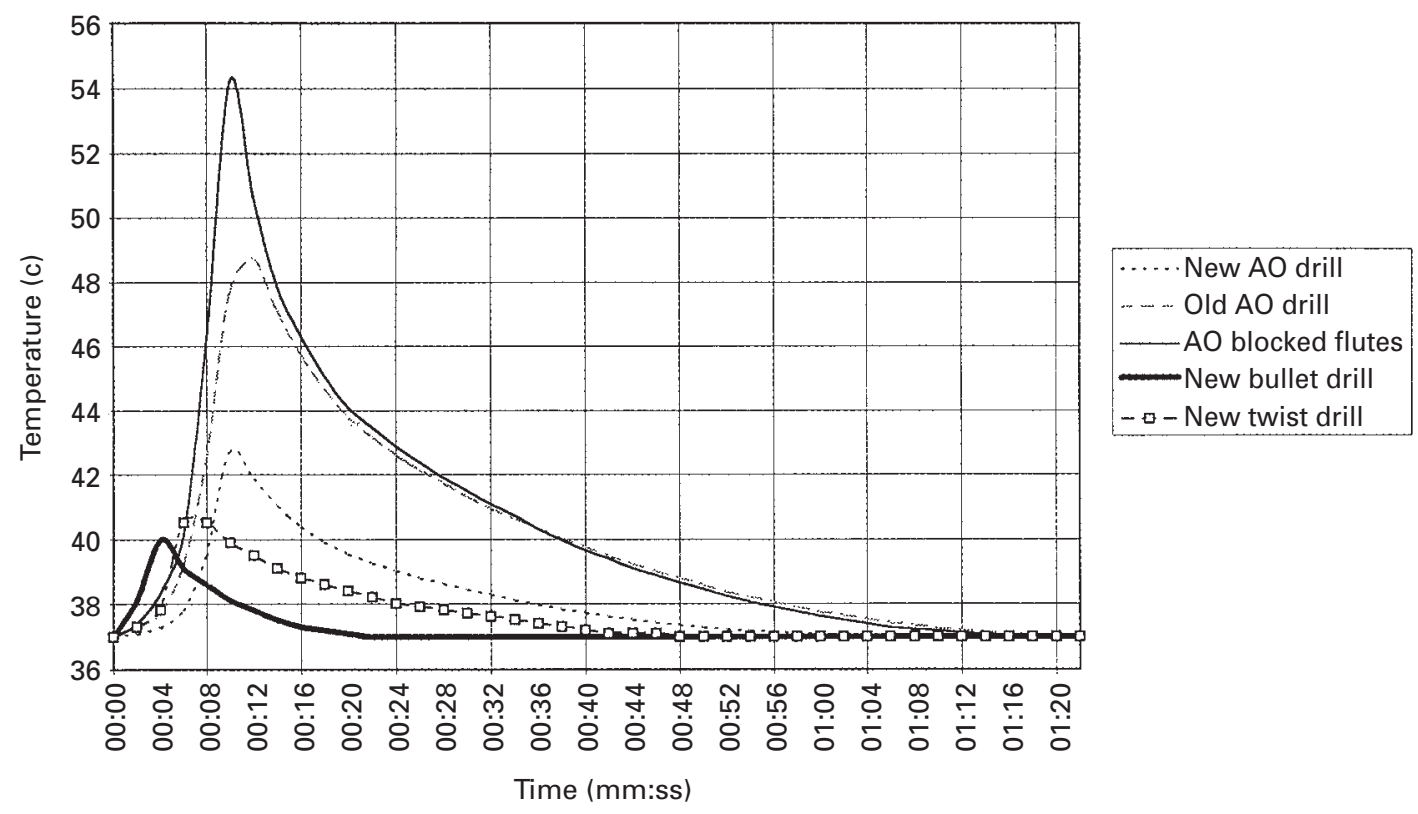

Fig. 9

Superimposed graphs of the temperatures at $0.5 \mathrm{~mm}$ from the drill edge.

cal operation. The maximum force required to achieve penetration of one cortex was in the order of $20 \mathrm{~N}$ using a new Stratec drill bit, but less than $10 \mathrm{~N}$ when using a 'Bullet' drill bit. The ease of cortical penetration can be inferred from the temperature recordings in Figure 9 which show the smaller duration and lower maximum temperature rise for 
this drill. The conversion from kinetic to thermal energy is less for the 'Bullet' drill bit.

\section{DISCUSSION}

Thermal insult to living tissue causes damage and eventual cell death. It has been shown that heating above $50^{\circ} \mathrm{C}$ causes irreversible change to the physical properties of bone (Bonfield and Li 1968), probably because of changes in the collagen of the matrix. Cortical necrosis and delayed healing were reported in canine bone after heating to between $43.3^{\circ}$ and $68.7^{\circ} \mathrm{C}$ (Ardan, James and Herrick 1957). Our choice of $40 \cdot{ }^{\circ} \mathrm{C}$ was arbitrary, but we felt that thermal injury should be reduced to a known 'safe' level for local osteoblasts.

Blunt drills are all too common in orthopaedic theatres and we believe that this is a problem which should be addressed. The 'old drill bit' which we used was removed from a small fragment set chosen at random from our operating theatre. Blunt bits produce more thermal damage; in addition, the increased force required for penetration may result in sudden bursting through the cortex and may cause inadvertent damage to soft tissues. The increased force may also result in broken drill bits and possible injury to the surgeon from the sharp ends. There is a strong case for the early introduction of a drill bit that has been designed in the light of modern engineering practice.

Previous studies on the design of drill bits have provided conflicting advice. Our preliminary experiments in an open laboratory showed clearly that environmental temperature had a considerable effect on temperature recordings. This precluded the use of controlled feed rate drilling, but we consider that the method which we used closely resembled that encountered in the operating theatre. The reproducibil- ity of our recordings confirms the stability of the experimental conditions.

We have shown that use of a split-point drill bit, with a point angle of $118^{\circ}$ and a quick helix gives an improved performance, reducing the force required (and the time for heat generation), and therefore causing less thermal damage than a standard orthopaedic drill. Theory suggests that further improvements may be possible; we are now studying these in the laboratory, using custom-built drill bits. The problem of thermal injury when drilling bone is well known to surgeons, but as yet it is unresolved by the manufacturers of orthopaedic equipment.

This research was sponsored by a grant from the Wishbone Trust. We wish to thank Mr H. T. Ellis of Anglia University for his help in preparing the thermocouple holes, and Professor Stephen Evans of The London Hospital Medical College for help with statistical analysis. We also acknowledge the donation of new orthopaedic drills made by Stratec Medical, Welwyn Garden City, Herts, UK.

No benefits in any form have been received or will be received from a commercial party related directly or indirectly to the subject of this article.

\section{References}

Andrianne Y, Wagenknecht M, Donkerwolcke M, Zurbuchen C, Burny F. External fixation pin: an in vitro general investigation. Orthopedics 1987; $10: 1507-16$.

Ardan NL, James JM, Herrick JF. Ultrasonic energy and surgically produced defects in bone. J Bone Joint Surg [Am] 1957;39-A:394-402.

Bonfield W, Li CH. The temperature dependence of the deformation of bone. J Biomechanics 1968;1:323-9.

Fuchsberger A. Optimization of the spiral drill for use in medicine. $\mathrm{Z} \mathrm{Or}$ thop 1987;125:290-7.

Matthews LS, Green CA, Goldstein SA. The thermal effects of skeletal fixation-pin insertion in bone. J Bone Joint Surg [Am] 1984;66-A: 1077 83.

Matthews LS, Hirsch C. Temperatures measured in human cortical bone when drilling. J Bone Joint Surg [Am] 1972;54-A:297-308.

Saha S, Pal S, Albright JA. Surgical drilling: design and performance of an improved drill. J Biomech Eng 1982;104:245-52.

Sidak Z. Rectangular confidence regions for the means of multivariant normal distributions. J Am Stat Assoc 1967;62:626-33. 